East African Medical Journal Vol. 77 No. 3 March 2000

EPIDEMIOLOGY OF SINGLE AND MULTIPLE SPECIES OF HELMINTH INFECTIONS AMONG SCHOOL CHILDREN IN BUSIA DISTRICT, KENYA

S. Brooker, MA, Wellcome Trust Centre for the Epidemiology of Infectious Disease, University of Oxford, South Parks Road, Oxford OX1 3FY, UK., E.A Miguel, MA, Department of Economics, Littauer Center, Harvard University, Cambridge, MA 02138, USA, S. Moulin, MA, Development Economic Research Group - Poverty and Human Resources Division, The World Bank, 1818 H Street NW, Washington DC 20433, USA, A.I. Luoba, MS, Division of Vector Borne Disease, Ministry of Health, Kisumu, Nyanza Province, Kenya, D.A.P. Bundy, PhD, Wellcome Trust Centre for the Epidemiology of Infectious Disease, University of Oxford, South Parks Road, Oxford OX13FY, UK and M. Kremer, PhD, Department of Economics, Massachusetts Institute of Technology, E52251C, Cambridge, MA 02139. USA.

Request for reprints to: S. Brooker, Wellcome Trust Centre for the Epidemiology of Infectious Disease, University of Oxford, South Parks Road, Oxford OX1 3FY, UK.

\title{
EPIDEMIOLOGY OF SINGLE AND MULTIPLE SPECIES OF HELMINTH INFECTIONS AMONG SCHOOL CHILDREN IN BUSIA DISTRICT, KENYA
}

\author{
S. BROOKER, E.A MIGUEL, S. MOULIN, A.I. LUOBA, D.A.P. BUNDY and M. KREMER
}

\begin{abstract}
Objective: To describe the patterns of single and multiple helminth infection in school children from Busia District, Kenya.

Design: A cross-sectional school survey using a randomly selected sample, forming part of an evaluation study of an ongoing deworming project.

Setting: Budalangi and Funyula divisions of Busia District, Western Province, Kenya.

Subjects: One thousand seven hundred and thirty eight school children aged 8-20 years randomly selected from those enrolled in standards 3-8 in 25 randomly selected primary schools.

Results: Overall, 91.7\% of children were infected with either hookworm,Ascaris lumbricoides, Trichuris trichiura or Schistosoma mansoni. Infection prevalence of each species varied considerably among schools, being most marked for $S$. mansoni, where prevalence was highest in lakeshore schools. Children were typically infected with two or more species of helminth. Infection intensity of each geohelminth species was higher in school children infected with multiple species than in school children with single species infections, and intensity increased with the number of concurrent infections.

Conclusion: Helminth infections are exceptionally common among school children in Busia district, thus confirming the good sense of the school-based approach adopted by the control programme. The study also shows that there is an association between concurrent infection and the intensity of infection, which may have consequences for nutritional and educational status.
\end{abstract}

\section{INTRODUCTION}

Helminth infections are a major public health problem and cause under-nutrition and cognitive impairment(1-4), with school children typically experiencing the heaviest burden of disease(5). For each species of helminth the associated degree of morbidity is related to the intensity of infection $(3,6)$, whilst the degree of morbidity may also be related to the number of different species harboured(711). A recent study in Tanzania investigated the relationship between multiple species infections and the intensity of infection of each species and demonstrated that children infected with two or more species of helminths generally carry heavier infections of each species than children carrying single species infections(11).

This paper describes the epidemiological characteristics of single and multiple species infections in school children in Busia District where no surveys have been reported previously, and investigates the relationship between multiple species infections and intensity of infection. The work forms part of an evaluation study of a deworming project being implemented through the current educational activities of a Dutch NGO, Internationaal Christelijk Steunfonds (ICS). Here we report on the baseline survey, which had two aims: to describe the health status of school children in Busia, and to provide baseline information on health before delivering treatment.

\section{MATERIALS AND METHODS}

Study population: The study was conducted in Budalangi and Funyula Divisions of Busia District during January-March 1998. The present analyses describes the baseline survey of a randomised prospective evaluation of the educational impact of schools-based treatment, and includes school children in 25 randomly selected schools from the 75 rural schools in the two divisions. These schools form the initial treatment group in a study with a randomised order of treatment including the remaining 50 schools in two future rounds of evaluation with treatment being provided over successive years.

During parent teacher association meetings, community members had the purpose of the study explained to them in the language they felt most comfortable with and were asked if they wished their children to participate and asked to sign parental consent for treatment. Children were able to withdraw from the 
study at any point of the study. The study was approved by the Kenya Ministry of Health Ethical Committee.

Parasitology: Fifteen children in each of the standards 3 to 8 were selected randomly. Each child was given a plastic container and asked to provide a faecal sample. Samples were examined in duplicate within 24 hours using the Kato-Katz method for the eggs of hookworms, Ascaris lumbricoides, Trichuris trichiura and Schistosoma mansoni. The concentration of eggs was expressed as eggs per gram (epg).

Data analysis: To examine the prevalence of heavy infections, thresholds of intensity were defined. These were chosen in accordance with the distribution of egg counts within the population and were defined at the $90 \%$ percentile level.

The effect of age and sex on whether a child was infected or heavily infected was analysed using logistic regression. Since the distribution of egg counts is typically overdispersed, KruskallWallis analyses were used to assess the variation of egg counts by age, sex and multiple species infections. Poisson log linear analysis was undertaken to assess whether combinations of species were present in the same individual more than expected by chance using a simple probabilistic model $(11,12)$.

\section{RESULTS}

A total of 1738 children aged 8-20 years were randomly selected from 25 schools to participate in the study. The mean number of children in each school was 69 (range 4485).

The prevalence of infection and mean egg counts are summarised in Table 1. Overall, $91.6 \%$ of the children were infected with A. lumbricoides, $T$. trichiura, hookworm or $S$. mansoni. Hookworm was the most prevalent helminth (Table 1). For each species of infection there was a wide range in infection prevalences, especially for $S$. mansoni where prevalence was above $30 \%$ in only six schools, and only three schools situated directly on the lakeshore had a prevalence above $50 \%$. The overall prevalence of geohelminth species was greater than $50 \%$ in all 25 schools surveyed. Multiple species infections were very common: $5.9 \%$ of children harboured all four types of infections (range $0 \%-27.5 \%$, by school); $27.9 \%$ harboured three species infections (range 7.4\%-63.9\%, by school);
$31.2 \%$ harboured two species infections (range 5.9\%$45.9 \%$, by school).

In terms of identifying children requiring treatment for geohelminth and/or schistosome infection, $89.6 \%$ of children were infected with any geohelminth infection (range $70.8 \%-100 \%$, by school). A quarter (26\%) of children harboured all three species of geohelminth infection, with $31.1 \%$ harbouring both $A$. lumbricoides and $T$. trichiura, although this was typically in combination with hookworm since only $7.7 \%$ harboured $A$. lumbricoides and $T$. trichiura without hookworm infection. .Overall, $19.8 \%$ of children harboured both schistosome and geohelminth infection, although this ranged between schools from $1.4 \%$ to $77.3 \%$, being highest in the lakeshore schools. A majority of children $(71.9 \%)$ were infected either with schistosome or geohelminth species rather than a combination of geohelminth and schistosome infection: $2 \%$ of children were infected with S. mansoni only: and $69.9 \%$ of children were infected with geohelminth species only.

Logistic regression revealed that there was a significant relationship between being infected with $A$. lumbricoides infection and host age $(\mathrm{p}=0.02)$, with prevalence decreasing from $54.9 \%$ among children aged 6-9 years to $44.9 \%$ among children aged 18 years and above. In contrast, no significant relationship between host age and infection prevalence was observed for the other helminth species (Hookworm, $\mathrm{p}=0.395 ;$ T. trichiura, $\mathrm{p}=0.993 ;$ S. mansoni, $\mathrm{p}=0.711$ ). The prevalence of infection, heavy infection and mean egg count of hookworm infection and S. mansoni were significantly higher in boys than in girls (Table 2). There was no significant difference between the prevalence and intensity of A. lumbricoides and T. trichiura in boys and girls.

After adjusting for the effect of age in the Poisson loglinear analysis, there was evidence of excessive clustering of A. lumbricoides and T. trichiura, suggestive that concurrent infection with these species occurs at a greater frequency than would be expected by chance (Table 3 ). However, there was no excessive clustering of other

Table 1

Prevalence and mean egg counts of intestinal schistosomiasis and intestinal nematodes in schoolchildren in Kenya ${ }^{I}$

\begin{tabular}{|c|c|c|c|c|}
\hline \multirow[t]{2}{*}{ Species infection } & \multirow{2}{*}{$\begin{array}{l}\text { Prevalence } \\
\text { (range in schools) } \\
\%\end{array}$} & \multirow{2}{*}{$\begin{array}{l}\text { Heavy infection }{ }^{2} \\
\text { (range in schools) } \\
\%\end{array}$} & \multicolumn{2}{|c|}{ Intensity (epg) } \\
\hline & & & Mean & SD \\
\hline Hookworms & 77.5 (35.1-97.1) & $8.6(0-22.4)$ & 432 & 1070 \\
\hline A.lumbricoides & $41.9(21.3-93.6)$ & $4.5(0-27.7)$ & 2322 & 5138 \\
\hline T.trichiura & $55.2(20.8-94.7)$ & $3.9(0-14.9)$ & 161 & 464 \\
\hline S.mansoni & $22.0(2.8-97.3)$ & $4.5(0-49.9)$ & 89 & 413 \\
\hline
\end{tabular}

${ }^{1}$ Sample size: 8yrs-25, 9yrs-55, 10yrs-123, 11 yrs-137, 12yrs-262, 13yrs-297, 14yrs-289, 15yrs-264, 16yrs-170, 17yrs-77, 18yrs-39

${ }^{2}$ Hookworms 1,250+ epg; A.lumbricoides 20,000+ epg; T.trichiura 1,000+ epg; S.mansoni 500+ epg 
species combinations, indicating all other combinations of infections did not occur more or less than expected by a simple probabilistic model(13). This result suggests independence of transmission between these species.

Table 2

The prevalence and mean egg counts of intestinal schistosomiasis and intestinal nematodes by sex

\begin{tabular}{lccc}
\hline & $\begin{array}{c}\text { Males } \\
\mathrm{n}=943\end{array}$ & $\begin{array}{c}\text { Females } \\
\mathrm{n}=795\end{array}$ & $\begin{array}{c}\text { Significant } \\
\text { difference }(\mathrm{P})^{2}\end{array}$ \\
\hline \% infected & & & 0.0001 \\
$\quad$ Hookworms & 81.0 & 73.5 & 0.69 \\
A.lumbricoides & 42.1 & 41.6 & 0.34 \\
T.trichiura & 56.5 & 53.7 & 0.004 \\
S. mansoni & 24.5 & 18.7 & 0.02 \\
\% heavily infection & & & 0.36 \\
Hookworms & 10.2 & 6.9 & 0.74 \\
A.lumbricoides & 4.0 & 5.2 & 0.006 \\
T.trichiura & 3.7 & 4.0 & 0.0001 \\
S.mansoni & 5.7 & 3.0 & 0.98 \\
Mean egg count & & & 0.46 \\
Hookworms & 493 & 371 & 0.002 \\
A. Iumbricoides & 2247 & 2410 & 169 \\
T.trichiura & 153 & 66 & \\
S.mansoni & 108 & & \\
\hline
\end{tabular}

${ }^{1}$ Hookworms 1,250+ epg; A.lumbricoides 20,000+ epg; T.trichiura 1,000+ epg; S.mansoni $500+$ epg

${ }^{2}$ Significance tested by logistic regression for prevalence and Kruskall-Wallis for egg counts.

Table 3

Poisson log-linear analysis of the interaction between species prevalence in 1739 school children in Busia Ditrict, Kenya. (Sign of regression estimate denotes the direction of the association. Significant result in bold)

\begin{tabular}{|c|c|c|c|c|}
\hline Infection combination & Estimate & $\begin{array}{l}\text { Standard } \\
\text { error }\end{array}$ & Chi-square & $P$ \\
\hline A.lumbricoides*Age & -0.041 & 0.039 & 1.1 & 0.3015 \\
\hline T.trichiura*Age & -0.013 & 0.035 & 0.1 & 0.7059 \\
\hline Hookworm*Age & 0.059 & 0.026 & 5.3 & 0.0216 \\
\hline S.mansoni*Age & 0.001 & 0.039 & 0.001 & 0.9713 \\
\hline A. lumbricoides*T. trichiura & 1.120 & 0.424 & 6.996 & 0.008 \\
\hline A. lumbricoides $*$ Hookworm & 0.398 & 0.498 & 0.6 & 0.4434 \\
\hline A. lumbricoides $* S$. mansoni & -0.145 & 0.499 & 0.08 & 0.7714 \\
\hline T. trichiura*hookworm & 0.726 & 0.498 & 2.1 & 0.1447 \\
\hline T. trichiura*S.mansoni & 0.098 & 0.514 & 0.03 & 0.8475 \\
\hline Hookworm*S.mansoni & -0.025 & 0.552 & 0.002 & 0.9644 \\
\hline A. lumbricoides $*$ T. trichiura $*$ Age & 0.013 & 0.031 & 0.2 & 0.6679 \\
\hline A. lumbricoides $*$ Hookworm $*$ Age & 0.007 & 0.038 & 0.02 & 0.8641 \\
\hline A. lumbricoides ${ }^{*}$ S. mansoni ${ }^{*}$ Age & 0.004 & 0.037 & 0.01 & 0.9145 \\
\hline T. trichiura*hookworm*Age & -0.019 & 0.036 & 0.3 & 0.5989 \\
\hline T. trichiura $*$ S. mansoni $*$ Age & 0.042 & 0.037 & 1.3 & 0.2629 \\
\hline Hookworm*S. mansoni*Age & -0.03 & 0.402 & 0.6 & 0.4386 \\
\hline Age & 0.009 & 0.023 & 0.2 & 0.6803 \\
\hline
\end{tabular}


Figure 1

Comparison of mean egg counts in the presence of single and concurrent species infection in 1739 school children in Busia district (vertical bars represent standard errors of the mean values and sample sizes are given in parenthesis) (a) hookworm; (b) A. lumbricoides, (c) T. trichiura and (d) S. mansoni
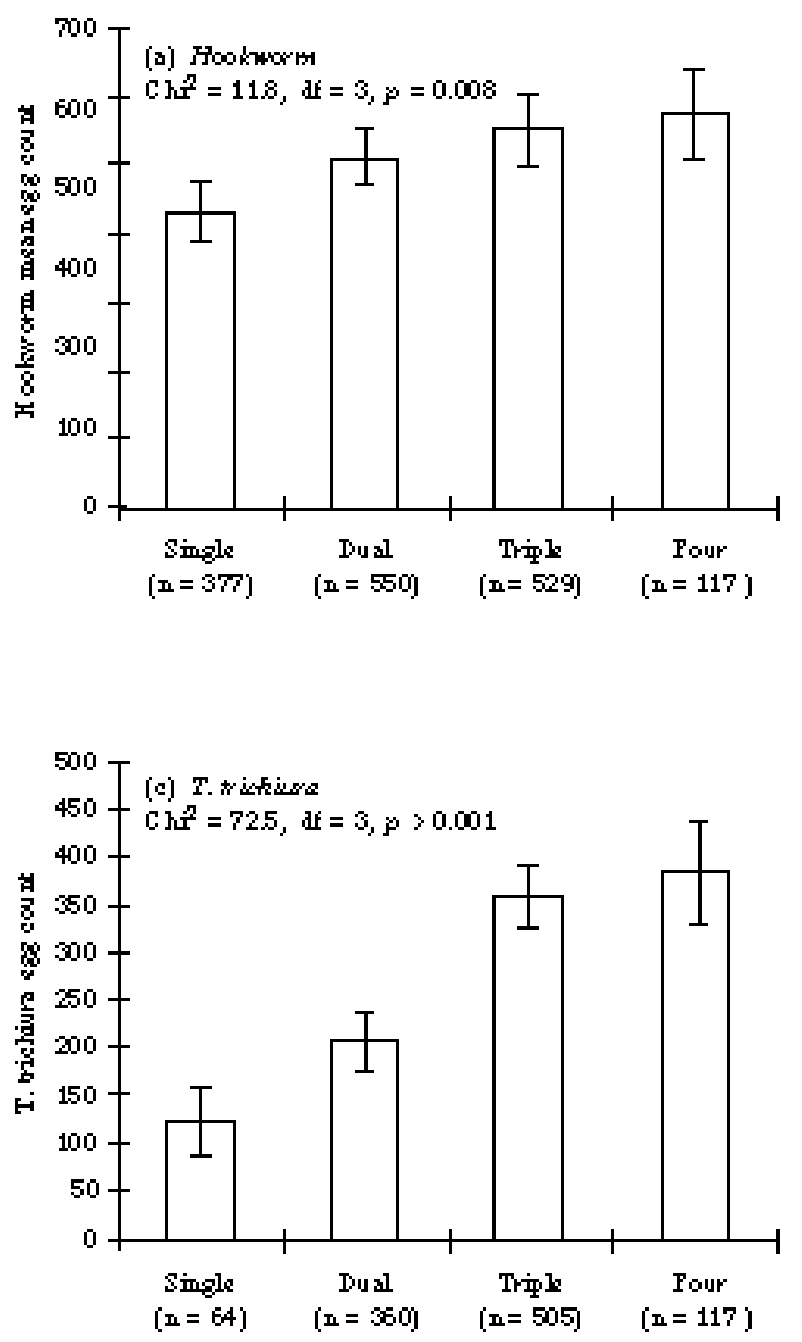

The relationship between multiple helminth species infection and mean intensity is depicted in Figure 1. For the geohelminth species, mean egg counts are significantly and increasingly higher in children with two or more species than children infected with single species. There is no significant difference in mean egg count of S.mansoni and the number of helminth species present and the trend in the data suggests an inverse relationship.

\section{DISCUSSION}

School-based helminth control programmes have been identified as one of the most cost-effective health interventions both in theory(5) and in practice $(14,15)$. For these reasons national and international organisations are promoting helminth control programmes which deliver praziquantel to treat schistosome infections and albendazole to treatment intestinal nematodes through the existing educational infrastructure(16). However, prior to
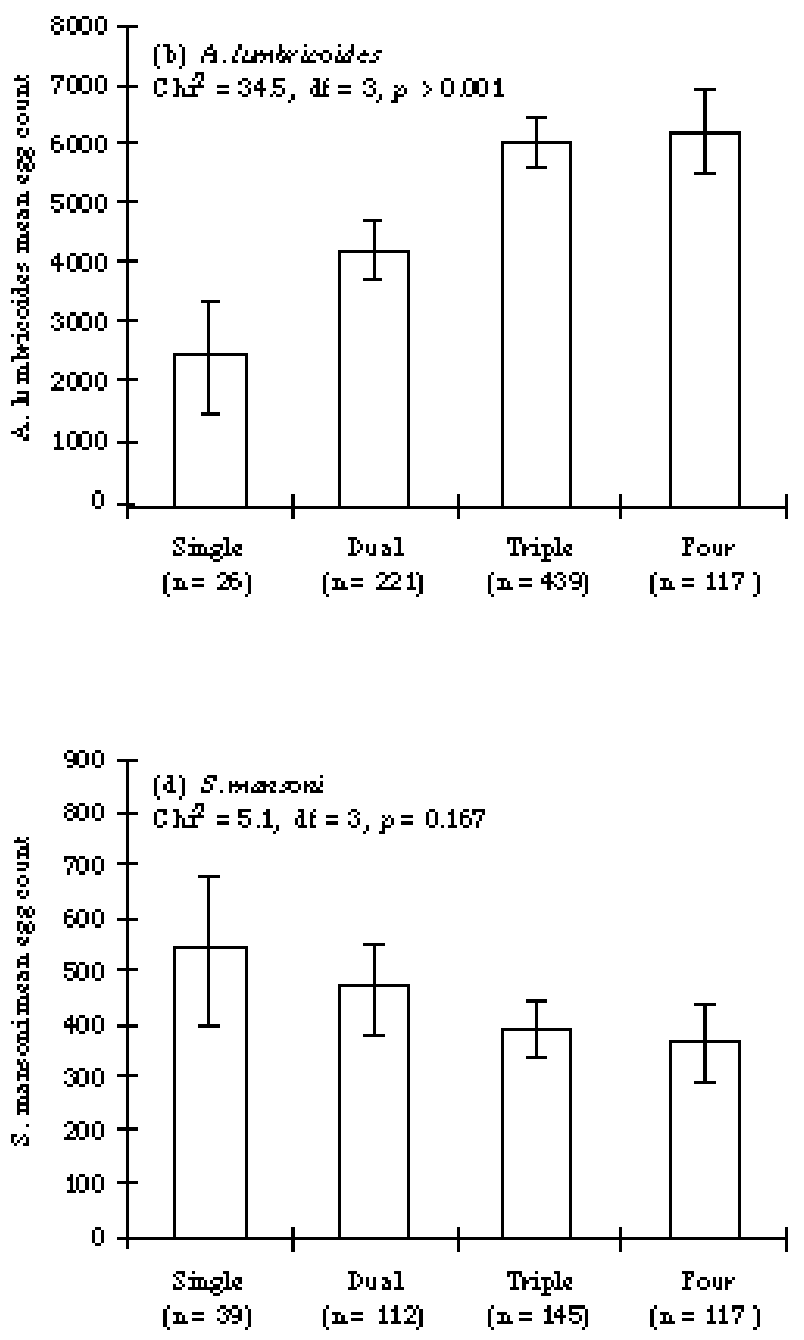

implementing such programmes it is necessary to evaluate the extent of the problem in the population(17). All of the schools surveyed in the present study had geohelminthiasis prevalence in excess of $50 \%$, thereby warranting mass treatment(17). However, mass treatment for schistosomiasis would be warranted in three schools only using the $50 \%$ threshold. It is notable that these schools were confined to the lakeshore. This strict relationship between S.mansoni prevalence and proximity to the lakeshore has been discussed elsewhere around Lake Victoria(18) and is attributed to the distribution of the intermediate snail hosts.

In accordance with other studies(11,13,19), the results demonstrated an association between the school prevalences of $A$. lumbricoides and T. trichiura (data not shown) and evidence of clustering of infection among individuals (Table 3). In contrast, there was evidence of independent transmission of hookworm and S. mansoni with all other species. This result is not surprising given the similarity of mode of transmission and epidemiology 
of A. lumbricoides and T. trichiura, and dissimilar transmission and epidemiology of hookworm and $S$. mansoni.

Our findings confirm that many children harboured several helminth species, which appears to be the norm rather than the exception in $\operatorname{Kenya}(20,21)$. We have demonstrated that children with multiple species infections have a higher egg count of each geohelminth species than children with single species infection. This agrees with similar observations on school children in Pemba(11), but contrasts with the results of a study in Morogoro, Tanzania.

This is an important observation since it implies that children with multiple species infections may also suffer multiple morbidity insults due to each species infection. Evidence from South Africa has indicated that school performance is related to concurrent infections, with children carrying multiple species infections having poorer school performance than those children uninfected or infected with a single species(10). However, this study looked at a small number of mainly cognitive outcome measures and it was unclear what would be the effect of parasite load on a broad range of educational indicators.

In conclusion, the overall prevalence of infection confirms the good sense of the school-based approach adopted by the control programme. This study has shown that children in Busia district are heavily infected and typically harbour multiple species infections, and that there is an association between concurrent infection and the intensity of infection. Future work will evaluate the impact of these multiple species infections, and the effect of intervention on a range of nutritional and educational outcomes.

\section{ACKNOWLEDGEMENTS}

To all the teachers and school children in the district for participating in the study, to the International Christelijk Steunfonds Africa (ICS) and the field staff for carrying out the fieldwork, especially Robert Namunyu, Laban Benaya, Polycarp Waswa, Moses Barasa, Petronilla Akoth and Hellen Mukanda. This work was supported by World Bank and the Partnership for Child Development, a consortium of donors, countries and technical institutions to develop the inter-sectoral collaborations necessary to establish or strengthen school health programmes. The Partnership for Child Development is supported by the United Nations Development Programme, the Rockefeller Foundation, the Edna McConnell Clark Foundation, the James S. McDonnell Foundation, the Wellcome Trust, the World Bank, UNICEF, and the World Health Organization. SB and DAPB would like to acknowledge the support of the Wellcome Trust. We acknowledge Andrew Hall and Helen Guyatt for their helpful advice.

\section{REFERENCES}

1. Booth, M. and Bundy, D.A.P. Comparative prevaences of Ascaris lumbricoides, trichuris trichuira and hookworm infections and the prospects for control. Parasitol. 1992; 151-157.

2. Stephenson, L.S. Impact of Helminth Infection in Human Nutrition. New York: Taylor and Francis, 1987.

3. Stoltzfus, R.J., Albonico, M. Chwaya, H.M., Savioli, L., Tielsch, J.M., Schulze, K.J. and Yip, R. Hemoquant determination of hookworm-related blood loss and its role in iron deficiency in African children. Amer. J. trop. Med. Hyg. 1996; 55:399-404.

4. Watkins, W.E. and Pollitt, E. "Stupidity or Worms": do intestinal worms impair mental performance? Psychol. Bull. 1997; 121:171191.

5. Warren, K.S., Bundy, D.A.P., Anderson, R.M., Davis, A.R., Henderson, D.A, Jamison, D.T., Prescott, N. and Senft, A. Helminth infections. In: Disease Control Priorities in Developing Countries (ed. Jamison, D.T., Mosley, W.H., Measham, A.R. and Bobadilla, J.L.). Oxford: Oxford University Press. pp. 131-60: 1993.

6. Ramdath, D.D., Simeon, D.T., Wong, M.S. and GranthamMcGregor, S.M. Iron status with varying intensities of Trichuris trichiura infection. Parasitol. 1995; 110:347-351.

7. Buck, A.A., Anderson, R.I., MacRae, A.A. and Fain, A. Epidemiology of poly-parasitism. I. Occurrence, frequency and distribution of multiple infections in rural communities in Chad, Peru, Afghanistan, and Zaire. Trop. und Parasitol. 1978a; 29:6170 .

8. Buck, A.A., Anderson, R.I., MacRae, A.A. and Fain, A. Epidemiology of poly-parasitism. I. Combined effects on the state of health. Trop. und Parasitol. 1978b; 29: 253-268.

9. Robertson, L.J.,Crompton, D.W.T., Sanjur, D. and Nesheim, M.C. Haemoglobin concentrations and concomitant infections of hookworm and Trichuris trichiura in Panamanian primary school children. Trans. roy. Soc. trop. Med. Hyg. 1992; 86:654-656.

10. Kvalsvig, J.D, Cooppan, R.M. and Connolly, K.J. The effects of parasite infections in cognitive processes in children. Ann. trop. Med. Parasit. 1991; 85:531-568.

11. Booth, M., Bundy, D.A.P., Albonico, M., Chwaya, H.M., Alawi, K.S. and Savioli, L. Associations among multiple geohelminth species infections in school children from Pemba Island. Parasitol. 1998a; 116:85-93.

12. McCullagh, P. and Nelder, J.A. Generalized Linear Models. Chapham and Hall, London, 1991.

13. Booth, M. and Bundy, D.A.P. Estimating the number of multiplespecies geohelminth infections in human communities. Parasitol. 1995; 111:645-653.

14. Partnership for Child Development. Better health, nutrition and education for the school-aged child. Trans. roy. Soc. Trop. Med. Hyg. 1997; 91:1-2.

15. Partnership for Child Development. Cost of school-based drug delivery in Tanzania. Hlth Pol. Plan. 1998; 13:384-396.

16. Hall, A., Orinda, V., Bundy, D.A.P. and Broun, D.Promoting child health through helminth control - a way forward? Parasitol. Today, 1997; 13:411-413.

17. WHO. Guidelines for the evaluation of soil-transmitted helminthiasis and schistosomiasis at the community level. Schistosomiasis and Intestinal Parasite Unit, Division of Control of Tropical Diseases, World Health Organization, Geneva. WHO/ CTD/SIP/98. $1,1998$.

18. Lwambo, N.J.S., Siza, J.E., Brooker, S., Bundy, D.A.P. and Guyatt, H. Patterns of concurrent infection with hookworm and schistosomiasis in school children in Tanzania. Trans. roy. Soc. trop. Med. Hyg. 1999; 93:497-502.

19. Booth, M., Mayombana, C. and Kilima, P. The population biology and epidemiology of schistosome and geohelminth infections among school children from Tanzania. Trans. roy. Soc. trop. Med. Hyg. 1998b; 92:491-495.

20. Chunge, R. N., Karumba P. N., Nagelkerke, N., Kaleli, N., Wamwea, M., Mutiso, N., Andala, E.O. and Kinoti, S.N. Intestinal parasites in a rural community in Kenya: crosssectional surveys with emphasis on prevalence, incidence, duration of infection, and polyparasitism. East Afr. Med. J. 1991; 68:112-23.

21. Chunge, R. N., Karumba P. N., Ouma, J.H., Thiongo, F.W., Stulrock, R.F. and Butterworth, A.E. Polyparasitism in two rural communihes with endemic Schistosoma mansoni infection in Machakos District, Kenya. J. trop. Med. Hyg. 1995; 98:440-444. 